\title{
A EXTENSÃO UNIVERSITÁRIA A SERVIÇO DA POLITIZAÇÃO DE ADOLESCENTES DE BAIRROS PERIFÉRICOS: O CASO DA OFICINA DE CULTURA POLÍTICA EM PROJETO DA UFJF ${ }^{1}$
}

\section{The university extension at the service of the politicization of teenagers from suburbs: the case of the workshop of political culture in the UFJF project}

\section{La extensión universitaria a servicio de la politización de los adolescentes de los suburbios: el caso del taller de la cultura política en el proyecto de UFJF}

\author{
Paulo Roberto Figueira Leal ${ }^{2}$ \\ Rafael do Nascimento Grohmann ${ }^{3}$ \\ Rodrigo Souza Silva ${ }^{4}$
}

\begin{abstract}
RESUMO
O artigo apresenta os resultados da oficina de Cultura Política desenvolvida no âmbito do projeto de extensão e pesquisa Comunicação para a cidadania, financiado pela Universidade Federal de Juiz de Fora (UFJF), pela Fapemig e pelo Ministério da Cultura. Nesta oficina, ministrada em 2008 e 2009 a jovens de escolas públicas provenientes de bairros periféricos de Juiz de Fora (MG), buscou-se verificar quais eram os valores políticos dos adolescentes e o quanto dessas visões decorria das informações recebidas por eles da mídia (pressupondo-se que os valores hegemônicos seriam majoritários na circulação midiática e, portanto, estariam presentes nas opiniões). Paralelamente, pretendia-se efetivar com eles discussões temáticas específicas, relacionadas à política, a partir de valores contra-hegemônicos, de modo a levá-los à reflexão crítica e, se possível, à ação efetiva.
\end{abstract}

Palavras-chave: comunicação; política; extensão.

\begin{abstract}
This article presents the results of a Political Culture workshop, placed within a research and extension program called Communication For Citizenship, sponsored by the UFJF, Fapemig and the Brazilian Ministry of Culture. The workshop took place in 2008 and 2009 with adolescents from public schools of distinct
\end{abstract}

\footnotetext{
${ }^{1}$ A oficina de Cultura Política integra o projeto Comunicação para a cidadania: tecnologias, identidade e ação comunitária, financiado pela UFJF, Fapemig e Ministério da Cultura.

2 Doutor e mestre em Ciência Política pelo Iuperj, jornalista pela UFRJ. Professor do Programa de Mestrado em Comunicação da Universidade Federal de Juiz de Fora (UFJF). Autor dos livros Identidades midiáticas (Ed. E-Papers, 2009), Identidades políticas e personagens televisivos (Editora Corifeu, 2007), O PT e o dilema da representação política (Editora da Fundação Getúlio Vargas, 2005) e Os debates petistas no final dos anos 90 (Editora Sotese, 2004). Endereço: Rua Wantuil Duque de Moraes, 307, Laranjeiras, Valença-RJ, CEP 27600-000; Telefones: (24) 2453-2162; (32) 9114-5186. E-mail: pabeto.figueira@uol.com.br

${ }^{3}$ Mestrando em Ciências da Comunicação pela Universidade de São Paulo (USP), sociólogo graduado pela Universidade Federal de Juiz de Fora (UFJF). Professor da Universidade de Taubaté (Unitau). E-mail: rafael-ng@uol.com.br

${ }^{4}$ Graduando em Comunicação da UFJF; ex-bolsista PET - MEC/Sesu. E-mail: rodsouzas@gmail.com
} 
peripheral neighborhoods in the city of Juiz de Fora (MG). The project aimed at uncovering the political values of those teenagers and assessing how much of these values were motivated by the media (assuming they would emerge during the discussion since hegemonic values are majority in the media). Moreover, there were efforts to discuss specific subjects, related to politics, based on counter-hegemonic values, leading them to develop critical thinking and, if possible, to effective actions.

Keywords: communication; politics; extension.

\title{
RESUMEN
}

\begin{abstract}
El artículo presenta los resultados del taller de la Cultura Política desarrollada en el marco del proyecto de extensión y pesquisa Comunicación para la Ciudadanía, financiado por la UFJF, por la Fapemig y por el Ministerio de Cultura. Este taller, realizado en 2008 y 2009 a los jóvenes de las escuelas públicas de los suburbios de Juiz de Fora (MG), trató de determinar cuáles eran los valores políticos de los adolescentes y lo cuánto estas visiones resultaba de la información recibida por ellos de los medios de comunicación (en el supuesto que los valores hegemónicos serían mayoría en el movimiento de los medios de comunicación y, por lo tanto, estarían presentes en las opiniones). Además, se ha pretendido cumplir con ellos discusiones temáticas específicas relacionadas con la política, desde valores contra-hegemónicos, a fin de someterlos a la reflexión crítica y, si es posible, a la efectiva acción.
\end{abstract}

Palabras clave: comunicación; política; extensión.

\section{Introdução}

O presente artigo apresenta os resultados da oficina de Cultura Política ministrada no projeto de pesquisa e extensão Comunicação para a cidadania: tecnologias, identidade e ação comunitária, financiado pela UFJF, Fapemig e Ministério da Cultura. O objetivo geral do projeto é contribuir para a democratização da comunicação e para o exercício da cidadania de jovens de bairros periféricos de Juiz de Fora (MG), estudantes de escolas públicas.

A esses jovens foram oferecidas atividades em oficinas, conduzidas por professores da Faculdade de Comunicação da Universidade Federal de Juiz de Fora (UFJF) e seus bolsistas de iniciação científica e de extensão, que procuravam estimular uma maior reflexão dos participantes com relação aos conteúdos midiáticos. Foram seis as oficinas: Novas Tecnologias, Jornal Impresso, Rádio, Fotografia, TV e Cultura Política. É a esta última oficina que este artigo se refere.

A oficina de Cultura Política buscava refletir mais diretamente sobre o contexto político contemporâneo e o significado dessa instância tão pouco compreendida e explorada por parcelas significativas da juventude. Uma das metas da oficina era verificar quais eram, no momento de chegada, os valores políticos desses jovens, e o quanto dessas visões decorreria das informações recebidas por eles da mídia (pressupondo-se que os valores hegemônicos seriam majoritários na circulação dos meios de comunicação de massa $e$, portanto, estariam presentes nas opinióes dos adolescentes).

Paralelamente, pretendia-se efetivar com eles discussões temáticas específicas, relacionadas à política, a partir de valores contra-hegemônicos, de modo a levá-los à reflexão crítica e, se possível, à ação efetiva: a partir das atividades trabalhadas com os jovens, procurou-se conduzi-los não só a repensar as possibilidades de ação política na comunidade e na escola, entre outros espaços, mas a efetivamente terem condições de implementá-las.

Em 2008, a base territorial trabalhada pelo projeto foi a Escola Municipal Santa Cândida, localizada no bairro homônimo da Zona Leste de Juiz de Fora. As atividades iniciaram-se com 16 adolescentes, entre 14 e 17 anos, cursan- 
do entre a quinta e a nona séries, dos quais sete chegaram ao final das atividades, seis meninas e apenas um menino. Segundo Lahni et al. (2009), o grande número de desistências se deveu, principalmente, às premências de inserção de muitos deles no mercado de trabalho, já que o projeto não disponibilizava bolsas.

As oficinas foram realizadas na Casa de Cultura/UFJF, entre os meses de agosto $e$ novembro de 2008. Além daquelas relacionadas à comunicação, a Faculdade de Serviço Social também acompanhou o grupo de adolescentes, com encontros quinzenais, nos quais foram trabalhados aspectos socioeducativos juntamente a outros temas delineados pelo projeto.

Já no primeiro semestre de 2009, o projeto Comunicação para a cidadania passou a integrar o programa Educação e Cultura Geracional, financiado pelo Ministério da Cultura (o que levou à possibilidade de ofertar bolsas para os adolescentes), e 30 jovens dos bairros São Pedro, Santa Cândida e Dom Bosco foram selecionados para frequentar as oficinas - no primeiro semestre, 15 deles iniciaram os encontros de Cultura Política.

Mas, ao chegarem aos primeiros encontros da oficina, que valores políticos tinham os jovens dessas turmas e o quanto dessas visões decorria do consumo midiático? É a discussão que segue.

\section{Valores ideológicos e mídia}

Berger e Luckmann (1985) sustentam que a percepção que cada um de nós tem da realidade decorre, fundamentalmente, dos processos de socialização e das interações que desenvolvemos com outros indivíduos e instituições - essas relações comunicativas nos oferecem universos simbólicos compartilhados fundamentais para nossa percepção e atribuição de significado às coisas do mundo e a nós mesmos.
Já Goffman (1974) aponta que os enquadramentos (entendidos como modelos de interpretação e seleção que definem ênfases e exclusões utilizadas para organizar o discurso) constituem recortes culturais cruciais para a organização de nossas visões de mundo. Também o sistema contemporâneo da mídia - tão importante como fonte de informação e transmissão de valores para milhões de cidadãos mundo afora - opera a construção de seus discursos por meios de enquadramentos, como observa Gitlin (1980).

Mas quais são as implicações disso na constituição da visão de mundo dos indivíduos? Num contexto em que, a cada dia mais, a esmagadora maioria das certezas não provém da experiência direta, mas de informações mediadas pelo aparato da comunicação de massa, é razoável supor que as valorações (explícitas ou implícitas) majoritárias no discurso da mídia impactam, em alguma medida, as visões daqueles que dependem excessivamente - ou exclusivamente - dessas fontes para formar juízo sobre a realidade.

Em outras palavras, valores ideológicos hegemônicos na mídia podem ser introjetados, em alguma proporção, por indivíduos e grupos. É preciso ressalvar o sentido que aqui se dá à expressão "ideologia". Mais do que mero posicionamento político, trabalha-se com a ideia gramsciana de que "todo homem é filósofo, ou seja, que todo homem manifesta em sua ação - através de sua linguagem, de seu senso comum, de suas crenças, etc. - uma concepção do mundo" (COUTINHO, 1980, p. 83).

No caso específico de visões sobre política que são oferecidas pela comunicação de massa (e que se supõe que possam ser incorporadas por alguns), dada a natureza empresarial dos grandes grupos de comunicação, é razoável afirmar que os valores ideológicos majoritariamente ofertados pelo discurso midiático tradicional encontram-se, do ponto de vista da escala esquerda - direita, mais à direita do que à esquerda. 
Vozes mais céticas à validade dessa escala poderiam perguntar: no momento histórico em que vivemos (pós-derrocada da experiência do socialismo real), ainda é possível falar em identidades ideológicas à esquerda ou à direita? Norberto Bobbio (2001) sustenta que sim. Desde a Revolução Francesa, quando as expressões "esquerda" e "direita" se popularizaram no jargão político, a dicotomia expressa, segundo Bobbio, profundas diferenças de valores.

Mesmo que se leve em conta que a distinção comporta numerosas posições intermediárias, há uma clara clivagem ideológica sobre a questão da igualdade entre os homens. A posição típica de esquerda assenta-se na suposição de que não apenas a causa da desigualdade é majoritariamente social como ela pode ser eliminada (crença de que não partilha a direita). As instâncias coletivas - dentre elas o Estado - seriam fundamentais para resolver esses problemas.

Se o discurso hegemônico, portanto, situa-se à direita e se, dentro dele, há uma prevalência da variante liberal, a compreensão da face contemporânea desse discurso engloba fundamentalmente as argumentações teóricas de pensadores liberais do século XX, como Friedrich August Von Hayek (1899-1992). Ele criou um arsenal discursivo baseado, sobretudo, na louvação das ações tomadas por agentes individuais (empresas ou indivíduos), mais eficientes, em sua opinião, do que as tomadas por atores coletivos.

Essa visão de desconfiança em relação às instâncias coletivas - mas também às capacidades de intervenção e de regulação da política em geral - é frequentemente expressa pela grande imprensa. Mas até que ponto ela é assimilada e internalizada (consciente ou inconscientemente) por jovens de regiões periféricas, cujo acesso à informação é fortemente limitado por conta de suas condições socioeconômicas? Eles incorporam os valores presentes nesse discurso de demonização do Estado - e, por associação deste como centro da atividade política, numa visão simplista, de demonização da própria política?

Apesar de serem jovens que, mais até do que outros, demandariam a capacidade de organização coletiva para a solução de problemas, eles manifestam-se próximos de uma visão individualista - tal como preconizado pelo ideário liberal? Tendo em mente essas questões, o projeto consistiu no acompanhamento - por meio da metodologia de observação participante, complementada por entrevistas e questionários - das opiniões políticas de jovens juizforanos que participaram da oficina de Cultura Política.

Em resumo, os pressupostos teóricos iniciais eram: a) Visões de mundo sobre a realidade e valorações ideológicas decorrem dos processos de socialização a que indivíduos são submetidos; b) Os meios de comunicação passaram, na contemporaneidade, a ser cada vez mais presentes nesses processos de socialização, pois constituem a fonte discursiva prioritária (às vezes única) para parcelas da sociedade; c) A mídia representa e vocaliza visões marcadas por valorações ideológicas - e, no caso da grande mídia empresarial, essas marcações encontram-se situadas à direita do espectro ideológico (sobretudo a partir da vertente liberal); d) Na leitura neoliberal, representada pelas ideias, por exemplo, de Hayek, as ações individuais são mais valorizadas que instâncias coletivas; e) Jovens de regiões periféricas de Juiz de Fora - por conta de suas condições socioeconômicas - tendem a depender excessivamente das informações que recebem de veículos de comunicação, sobretudo a TV, para formar suas próprias visões sobre o que seja política; f) Dentre essas visões, imagina-se que há uma predominância de concepções simplistas e negativas da política (derivadas de uma visão negativa das instâncias coletivas $e$ do Estado) e uma predominância de valores individualistas.

Partindo desse circuito lógico como rede de hipóteses, o trabalho da oficina tinha um duplo objetivo: verificar se isso efetivamente 
acontecia e, em caso afirmativo, apontar se as discussões ali realizadas - a partir de leituras contra-hegemônicas - poderiam conduzir os jovens à adoção de outras visões e outras práticas no espaço público, mais participativas e colaborativas. Seguem, adiante, resultados que apontam se os pressupostos iniciais foram ou não verificados.

\section{A presença da mídia na vida cotidiana e a depreciação da política}

Os resultados dos questionários respondidos pelos adolescentes nos primeiros dias da oficina de Cultura Política em 2008 e 2009, com um total de 36 respondentes, referem-se a turmas provenientes de bairros distintos que foram atendidos numa ou noutra oportunidade. Os jovens de São Pedro, Dom Bosco, São Benedito, São Sebastião, Santa Cândida e Granjas Betânia tinham, no momento das respostas, entre $14 \mathrm{e}$ 18 anos (com média de 16 anos).

As famílias de todos eles possuíam, no mínimo, um aparelho de televisão, e uma parcela significativa $(27,8 \%)$ possuía três aparelhos de TV em cores na residência. Além disso, 97,2\% tinham um aparelho de vídeo ou DVD, e a mesma porcentagem dispunha de, ao menos, um rádio.

A televisão ainda detinha crucial importância na vida dessas pessoas, já que 41,7\% afirmaram utilizá-la como principal veículo para busca de notícias sobre política. No entanto, como já têm apontado outros estudos, a Internet vem ganhando importância no cenário. Há de se destacar que $11,1 \%$ afirmaram não buscar em nenhum lugar notícias sobre política, o que já evidencia, em alguma medida, que a política não instigava a curiosidade de parte significativa desses jovens.

A centralidade televisiva era reforçada pela resposta à questão "horas por dia assistindo à TV": as respostas variaram de 2 a 13 horas, com média de 3,4 horas por dia. Ficava evidente que esse meio de comunicação ocupava um espaço central no dia a dia dessas pessoas. A maior parte delas $(86,1 \%)$ afirmava gostar do que via, ouvia ou lia, principalmente por ser interessante $(27,8 \%)$, pelo teor informativo $(25 \%)$ e pela diversão (22,2\%). Há de se enfatizar que, entre os que não gostavam do que viam, muitos apresentavam como motivo o fato de que as notícias eram ruins.

Com relação ao tipo de programa que mais gostavam de ver na televisão, os jovens tinham as seguintes opções: novela, telejornal, esportes, humorístico, desenhos e filmes. A maior parte dos pesquisados $(41,7 \%)$ assinalou todas ou quase todas as opções - o que evidenciava a preferência por um modelo de TV geralista (WOLTON, 2006) -, mas houve preponderância individual da novela, tendo a preferência de $27,8 \%$.

Sobre o mundo da política, $80,6 \%$ dos pesquisados afirmaram não se interessar por política. A justificativa mais usada, por $25 \%$ dos jovens, era de que a política seria "chata". Igual fatia de $25 \%$ dos respondentes não justificou a sua resposta. Outras justificativas dadas foram: "não gosto", "não entendo", "não voto", "porque é só corrupção". Entre os 19,4\% que afirmam se interessar pela área, houve justificativas como: "vou começar a votar", "porque traz conhecimento", "é legal", "é um meio de expressão", "para ver se os políticos cumprem as promessas", "para ver ideias novas".

Foi-lhes pedida uma definição de política: $33,4 \%$ não responderam ou não souberam dizer o que ela seria. A definição mais usada era a de política como perda de tempo, em 13,9\% dos casos - um bom indicativo do conceito negativo que eles, em sua maioria, tinham sobre o tema. Outras definições: "brigas", "eleição", "corrupção" (que, juntas, somam 22,2\%).

Poucos respondentes apresentaram visão dissonante dessa leitura depreciativa. As seguintes citações configuraram exceções: "direito de votar", "organização social", "governo", 
"partidos", "partidos eleitorais" (expressão que evidenciava a percepção de que os partidos políticos apenas funcionam em época de eleição), "pessoas com poder de melhorar a vida das pessoas", "relação com a vida cotidiana", "responsabilidade", "saber quem cuida da cidade", "tudo que envolve a sociedade".

Ou seja, por mais que alguns respondentes isolados enxergassem a presença da política na vida cotidiana, a maioria a via apenas na esfera eleitoral, do governo e dos partidos políticos, e não em suas próprias vidas. Política seria algo que não diz respeito a eles próprios nem trataria de coisas positivas. Na verdade, a maioria dos respondentes afirmava, direta ou indiretamente, querer se distanciar dela.

$\mathrm{Na}$ parte final do questionário, perguntou-se se eles tinham opinião formada sobre atores políticos como: algum partido, o presidente Lula e o prefeito da cidade de Juiz de Fora (Alberto Bejani, nas primeiras turmas, e Custódio Mattos, na última). Com relação ao partido político, a maioria $(77,8 \%)$ dizia não ter nenhuma opinião formada ou não respondeu. Os partidos foram mencionados por apenas três pessoas, que citaram PT, PSDB e PTB (sendo o PT considerado por duas pessoas). Dois nomes de políticos (Custódio Mattos e Carla Vidal) apareceram como "partidos políticos" em 11,2\% dos casos, o que evidencia, em certo medida, o fenômeno da personalização da política (WATTENBERG, 1991).

Com relação ao presidente Luís Inácio Lula da Silva, o número de casos sem resposta ainda era grande $(41,7 \%)$, mesmo sendo uma figura com mais visibilidade do que os partidos políticos. O campo semântico ao qual Lula foi mais relacionado era o de "bom presidente", em $30,6 \%$ dos casos. Outros casos isolados: "corrupto", "ladrão", "não gosto de Lula", "não é capacitado" ou "precisa fazer mais" poderiam ser colocados em um campo "negativo", com $14 \%$ dos casos. Ainda apareceram como respostas "PT" e "é o presidente".
Com relação aos prefeitos da cidade, mais uma vez foi predominante a opinião não formada sobre o assunto, o que ocorreu em $33,3 \%$ dos casos. Isso confirmava o distanciamento dos jovens em relação à política, associada a algo negativo. Em relação ao ex-prefeito Alberto Bejani (que foi eleito pelo PTB em 2004, mas renunciou em 2008 por causa de acusações de desvio de recursos), 16,7\% dos respondentes identificaram Bejani como "corrupto", 13,9\% como "safado, cachorro e sem-vergonha", e 5,6\% como "bandido" - corroborando a imagem negativa mostrada pelos jornais.

As últimas perguntas deste questionário inicial, respondido no primeiro encontro realizado pela oficina em cada turma, abordavam a participação dos jovens em alguma associação, seja ela de bairro, religiosa ou estudantil, por exemplo. $86,1 \%$ responderam negativamente à pergunta, com alguns justificando a não existência de um espaço como esse em seus bairros. Os $11,1 \%$ que responderam "sim" à pergunta participavam de associações religiosas, o que evidenciou a falta de pluralidade de espaços públicos nos bairros de regiões periféricas da cidade.

Em resumo, os dados revelados pelo questionário inicial reforçavam as hipóteses sobre o perfil dos jovens quando começaram as atividades da oficina: desinteressados por política, percebida por eles como algo limitado (e compreendida apenas na sua dimensão de disputa pelo poder do Estado, considerado negativamente) e não relacionada à vida de cada um. $\mathrm{Na}$ verdade, as soluções para seus problemas individuais ou os problemas coletivos de suas comunidades, na visão da maioria, não passavam pela política - ao contrário, demandavam sua negação.

Mas essas visões se mantiveram inalteradas ao longo das discussões? Uma vez instados a refletir sobre questões de política a partir de outro enfoque, durante os módulos, houve mudanças nas visões dos jovens? Para responder 
a essa questão, um questionário com respostas dissertativas foi aplicado à turma do primeiro semestre de 2008 ao fim das atividades, com perguntas sobre violência urbana, ações políticas e falta de oportunidades culturais e de emprego (o mesmo ocorrerá à frente com as turmas que ingressaram em 2009 no projeto).

As respostas trazem indícios de algum desenvolvimento e maior sofisticação política dos adolescentes. Há de se destacar, no entanto, que somente cinco pessoas responderam às questões, dado o esvaziamento da turma de 2008, que terminou com apenas sete alunos dos 16 que iniciaram o ano.

A primeira questão perguntava se problemas como a violência urbana, a dependência de drogas e a falta de oportunidades culturais e de emprego entre os jovens estariam ligadas a causas políticas. Em caso afirmativo, quais seriam essas causas. Todos responderam afirmativamente, e a ênfase maior foi na questão do emprego: "com a política podem ser criadas leis a favor da população, como o primeiro emprego", "oportunidades que não são dadas a essas pessoas, como um emprego digno, uma moradia", "em uma entrevista para emprego só será selecionada uma pessoa, e as causas são a falta de investimento para poder mudar esses problemas".

Como podemos observar, a falta de verbas e investimentos nessas áreas eram problemas destacados, "fazendo com que as pessoas sejam levadas a arrumar dinheiro de outra forma", "o mundo em que vivemos tem muita corrupção, e os nossos governantes não fazem o que realmente deve ser feito para melhorar e resolver estes problemas, surgindo, assim, a desigualdade e os problemas em comunidades carentes".

Após o diagnóstico desses problemas como causas relacionadas ao mundo da política, a segunda questão indagava: "quais são as ações políticas que podem ser desenvolvidas por você para lutar contra esses problemas?". Eles destacavam o grêmio estudantil, a associação do bairro, eventos culturais, palestras, conscientização sobre os problemas por meio da distribuição de folhetos, palestras, debates entre os jovens, criar uma ONG.

Ressaltavam também a importância do voto e da televisão como formas de protesto. Um dos jovens diz ainda que "não saberia organizar uma ação política", mas via que as pessoas às vezes faziam manifestações, não sabendo ele, no entanto, se os resultados eram positivos. Trata-se do caso mais descrente entre os jovens com relação à ação política. Mas mesmo aí fica clara a percepção do papel estratégico da comunicação nas lutas políticas - e da necessidade de que se desenvolvessem políticas de comunicação capazes de dar vozes a todos.

A terceira questão perguntava em quais espaços de atuação política o jovem poderia se envolver para melhorar sua vida e das pessoas ao seu redor e o que poderia ser feito nesses espaços. A maioria dos jovens apontava a importância da associação de bairro e da escola, por meio do grêmio estudantil, com um exemplo de grupo de jovens para promover espaços culturais, palestras, músicas, debates e festas.

É preciso ressaltar que esse foi o único exemplo prático dado pelos respondentes daquilo que poderia ser feito num espaço de atuação política - os outros apenas explicitaram os locais que podem servir de atuação política. E um dos jovens foi especialmente pessimista: "em nenhum, pois não sei que espaços são esses e não entendo o bastante de política para me envolver em um espaço de atuação para melhorar a vida de outras pessoas".

Ou seja, apesar de a maioria deles ter, ao longo da oficina, percebido que a política está relacionada aos seus problemas cotidianos (e que não se resume à disputa pelo poder do Estado nem deve ser negada), traços ideológicos que reiteravam uma visão de mundo marcada pelo individualismo ainda apareceram fortemente em respostas como essa. Mas as respostas nos questionários talvez sejam insuficientes para dar conta das valorações ideológicas profundas - e 
das mudanças ocorridas ao longo da oficina. Abordagens interpretativas da própria relação estabelecida nos encontros constituem evidências úteis para extrair inferências. É o que se segue.

\section{Como levar os jovens à reflexão crítica?}

Como os encontros da oficina tinham como objetivo discutir com os jovens as várias formas pelas quais poderiam agir politicamente em diferentes âmbitos da sociedade (demonstrando que política não é uma atividade restrita aos governantes), foram escolhidos temas que, de alguma maneira, tivessem relação com o cotidiano de suas comunidades. Foram tratadas questões como violência, racismo, falta de oportunidades, sexualidade, gênero, eleições, participação estudantil, território e espaço público e juventude e sua representação nos meios de comunicação.

Na perspectiva de extrair informações sobre as concepções dos jovens para além daquilo que eles responderiam nos questionários aplicados, os bolsistas do projeto estavam instruídos a observar as reações dos adolescentes enquanto os debates eram feitos, com base nos pressupostos e ferramentas de observação participante. Por causa da complexidade dos temas tratados (e também da resistência que os adolescentes tinham em relação ao tema), optou-se pela diversificação metodológica na condução dos encontros.

Apesar da valorização da produção oral - seja pelas exposições iniciais daquele que eventualmente conduzia a dinâmica, seja pelo estímulo à verbalização dos jovens -, outras atividades foram escolhidas para incentivar a movimentação e otimizar os níveis de participação. A escolha temática atendeu ao critério de trazer à tona assuntos relacionados à vida cotidiana.

Dessa maneira, no primeiro encontro da turma do segundo semestre de 2008, por exemplo, cujo tema era violência, a metodologia escolhida foi a oferta de um vídeo. Dada a existência, entre eles, de uma cultura audiovisual -e a centralidade da TV em suas vidas cotidianas era um indicador disso -, optou-se por exibir um trecho do documentário Notícias de uma guerra particular, de João Moreira Salles e Kátia Lund, de 1999.

O filme retrata o cotidiano dos moradores e traficantes do morro da Dona Marta, no Rio de Janeiro, a partir de entrevistas com pessoas que se encontravam, de alguma forma, próximas à rotina do tráfico de drogas. O objetivo era estabelecer comparações entre o que era mostrado pelo documentário e o que os jovens presenciavam no cotidiano, assim como fazê-los refletir sobre a forma naturalizada (e usualmente acrítica) com que viam a violência. Além disso, outras formas de violência, que não a física, foram abordadas, como a violência moral, a violência psicológica e a violência simbólica. Tentou-se, também, estimular uma visão crítica dos meios de comunicação, discutindo sobre como o bairro deles era representado pelos telejornais da cidade.

A participação dos jovens foi surpreendente. Eles relataram várias experiências que tiveram ou que presenciaram em relação aos vários tipos de violência, como brigas, vezes em que foram abordados pela polícia, ocasiões em que sofreram discriminação ao entrarem em lojas. Além disso, disseram gostar bastante de ouvir músicas, principalmente as dos gêneros funk, hip-hop e rap, pois se sentiam representados nas letras.

Assim, no segundo encontro com essa turma, optou-se por abordar o tema "racismo" com duas músicas: um samba, Canto das três raças, de Clara Nunes, e um rap, Racismo é burrice, de Gabriel Pensador. Buscou-se discutir a origem histórica do racismo e a participação política e cultural que os grupos excluídos têm na sociedade, sobretudo no que se refere aos negros. Os jovens refletiram também sobre como o negro é representado pelos meios de 
comunicação, principalmente nas novelas, nas quais quase sempre estão em menor número e exercendo papéis secundários. Por fim, a discussão chegou à politização da questão do racismo e do preconceito nas escolas.

O tema do encontro seguinte foi a falta de oportunidades, envolvendo as distintas classes sociais, e as diferenças de empregabilidade. Abordaram-se a educação $e$ a acessibilidade dos jovens em relação às escolas. Para isso, foi escolhido um trecho do documentário Pro dia nascer feliz, de João Jardim, como forma de iniciar a discussão. $\mathrm{O}$ filme aborda a realidade do sistema escolar brasileiro ao entrevistar alunos de 14 a 17 anos, de diferentes classes sociais, e professores de escolas públicas e particulares.

Procurou-se fazer com que os jovens refletissem acerca de seu próprio ambiente escolar, dos problemas e de como resolvê-los. Além disso, discutiu-se sobre espaços culturais dentro das escolas, como atividades envolvendo música, esportes, e sobre formas de participação dos alunos, como grêmios estudantis.

Os temas "sexualidade" e "gênero" foram abordados em um mesmo encontro. A metodologia escolhida para essa oficina foi o estímulo à produção criativa dos jovens: eles montaram painéis com imagens publicitárias, de forma a estimular a consciência crítica em relação a estereótipos femininos e masculinos em diversos âmbitos que são frequentemente veiculados nos meios de comunicação. Várias imagens relacionadas aos temas foram recortadas de revistas e jornais.

Em seguida, foi pedido que eles escolhessem as imagens que lhes chamassem mais a atenção. Logo após, discutiu-se sobre o que os motivou a escolher tais fotos, problematizando os elementos retratados. Entre os temas discutidos estavam os papéis sociais que são comumente associados ao homem e à mulher, questões envolvendo homossexualidade, preconceito $e$ formas de combatê-lo.

Como política envolve também a questão dos representantes que escolhemos pelo voto e como estávamos em época de eleições para a prefeitura da cidade, o tema do encontro seguinte foi o cenário eleitoral. Depois de responderem a algumas questões, foram exibidos programas de TV do horário de propaganda eleitoral gratuita, de maneira a fazer com que apontassem o que estava proposto pelos candidatos. No entanto, as críticas feitas pelos jovens centraram-se nos próprios programas, considerados "chatos", e não em relação ao conteúdo das propostas.

As opiniões verbalizadas pelos adolescentes sobre os candidatos provieram mais de imagens e informações externas aos programas, como boatos e históricos dos candidatos, do que de alguma reflexão suscitada pelos programas. Os elementos de despolitização e de não percepção das questões ideológicas de fundo revelavam-se mais uma vez: a demonização do poder público foi outro traço perene - bem em conformidade com uma identidade ideológica liberal, reverberada pela mídia, que sistematicamente associa tudo que é público ou estatal à ineficiência.

No encontro que abordou o tema "participação estudantil", foi utilizada outra plataforma de comunicação: a Internet. O objetivo era incentivar os jovens a realizarem pesquisas sobre assuntos diversos e mostrar para eles que a rede tem muitas possibilidades além de sites de relacionamento e programas de mensagens instantâneas. Além disso, preferiu-se ampliar a discussão para movimentos sociais, nos quais a participação estudantil estaria incluída. Para tal, algumas palavras foram sorteadas entre os jovens. Entre elas, "movimento estudantil", "movimento negro", "movimento feminista", "movimento dos sem-terra" e "grêmio estudantil".

Os jovens se organizaram em duplas, cada uma dividindo um computador e tendo a meta de pesquisar sobre o movimento que havia sorteado. Após a pesquisa, o grupo se reuniu em uma roda para partilhar a pesquisa realizada, opiniões sobre os movimentos e ideias para a criação de novos grupos para lutar por causas distintas. 
Na oficina seguinte, o tema foi "espaço público e privado". Neste encontro, cujo objetivo era a desmistificação da imagem de ineficiência e de mau funcionamento que comumente é associada à palavra "público", debateu-se a necessidade de valorizar a ação coletiva em detrimento de uma perspectiva individualista. Para isso, houve uma breve discussão sobre quais espaços seriam públicos e quais seriam privados, a diferença entre os conceitos, sobre como a sociedade se relacionava com o espaço público, além de possíveis formas de atuação. Os jovens associaram "espaço público" a um lugar onde todos podem entrar, estar, e "privado" como algo pertencente a alguém, só sendo possível a entrada quando permitida.

Posteriormente, eles levantaram questões sobre espaços comerciais e igrejas, refletindo sobre se estes seriam espaços públicos ou privados. Em seguida, foi pedido aos jovens que fizessem cartazes com desenhos, colagens e frases sobre espaços públicos, envolvendo problemas e possíveis soluções. A dificuldade inicial de que eles percebessem a dimensão do que seja público provavelmente revela a marca ideológica mais clara a demonstrar-se como estruturante de suas valorações e visões de mundo: o individualismo.

O último tema abordado foi a relação entre juventude e os meios de comunicação. Propôs-se aos jovens que fizessem um jornal mural para exposição na mostra que finalizaria o projeto. Assim, eles puderam refletir e discutir sobre os mais variados assuntos abordados durante todo o decorrer da oficina, relacionando-os com os meios de comunicação. Foram utilizados trechos de músicas, poesias, imagens, notícias, frases e desenhos. O mural foi exibido durante uma mostra que também expôs os trabalhos desenvolvidos em todas as outras oficinas.

\section{Considerações finais}

As hipóteses iniciais se confirmaram: uma vez tendo formado juízo sobre política a partir dos enquadramentos dados pela comunicação de massa - que normalmente a associam apenas à disputa pelo poder e aos eventuais escândalos dela decorrentes -, as visões dos adolescentes eram marcadas, ao iniciarem a oficina, por uma leitura simplista e negativa da política. Eles não percebiam as possibilidades de atuação política fora dos espaços eleitorais nem conectavam a política às possibilidades de resolução de seus problemas individuais ou coletivos.

As marcas do individualismo e da demonização das esferas públicas de atuação (em especial do Estado) - traços relevantes da identidade ideológica liberal, hegemônica nos discursos midiáticos - também apareceram com intensidade nas falas e textos produzidos pelos adolescentes, sobretudo nos momentos iniciais.

Contudo, mesmo que longe de um patamar que possa ser considerado ideal, o percurso da oficina oferece evidências de que processos de reflexão e de estímulo à ação no espaço público ali se iniciaram. Além dos indicativos já extraídos das respostas dos jovens nos questionários e de suas participações nos encontros, dados posteriores indicam as potencialidades de ações como esta.

$\mathrm{O}$ fato de que algumas adolescentes, a partir da oficina, empreenderam esforços para organizar um grêmio (até então inexistente) em sua escola, ou de que outras tenham tomado a iniciativa de procurar a associação de moradores de seu bairro para instalar uma Comissão de Juventude, aponta para a possibilidade de que muitos jovens tenham caminhado em direção à politização. 
Entende-se aqui politização por capacidade de reflexão, de escolha autônoma, de organização coletiva e de interferência na realidade. Se essa combinação se impuser e for capaz de oferecer contrapesos à posição hegemônica, cria-se uma potencialidade crítica de reação aos discursos que ocultam suas dimensões ideológicas - e todo discurso é ideológico. Desse modo, a percepção de que a vida no espaço público é capaz de impactar cada vida privada é, em grande medida, um avanço que conduz os jovens à atuação política mais do que à mera replicação de valores naturalizantes do individualismo $e$ da inação.

\section{REFERÊNCIAS}

BERGER, Peter; LUCKMANN, Thomas. A construção social da realidade: tratado de sociologia do conhecimento. Petrópolis: Vozes, 1985.

BOBBIO, Norberto. Direita e esquerda. São Paulo: Unesp, 2001.

COUTINHO, Carlos Nelson. Fontes do pensamento politico. Rio de Janeiro: L\&PM, 1980.

FIORIN, José Luiz. Linguagem e ideologia. 8. ed. São Paulo: Ática, 2004. (Série Princípios).

GITLIN, Todd. The whole world is watching: mass media in the making and unmaking of the new left. Berkeley: University of California Press, 1980.

GOFFMAN, Erving. Frame analysis: an essay on the organization of experience. New York: Harper and Row, 1974.

HAYEK, Friedrich August Von. O caminho da servidão. Rio de Janeiro: Instituto Liberal, 1990.
LAHNI, Cláudia (Coord.). et al. Projeto de Extensão da UFJF trabalha educomunicação com adolescentes de escola pública. In: CONGRESSO BRASILEIRO DE EXTENSÃO UNIVERSITÁRIA, 4., 2009, Dourados (MS). Anais... Dourados, 2009.

LEAL, Paulo Roberto Figueira. A construção discursiva da identidade política liberal na contemporaneidade: a incerteza como chave identitária e como argumento de comunicação de massa. In: __. Comunicação: tecnologia e identidade. Rio de Janeiro: Mauad X, 2007. p. 183-195.

WATTENBERG, Martin. The rise of candidate-centered politics: presidential election of the 1980s. Cambridge: Harvard University Press, 1991.

WOLTON, Dominique. Elogio do grande público: uma teoria crítica da televisão. São Paulo: Ática, 2006.

Texto aprovado em 18 de novembro de 2010. 